\title{
इㄴ. \\ Constructions: a new theoretical approach to language
}

\author{
Adele E. Goldberg \\ Linguistics Department, University of Illinois, Urbana, IL 61801-0168, USA
}

\begin{abstract}
A new theoretical approach to language has emerged in the past $10-15$ years that allows linguistic observations about form-meaning pairings, known as 'constructions', to be stated directly. Constructionist approaches aim to account for the full range of facts about language, without assuming that a particular subset of the data is part of a privileged 'core'. Researchers in this field argue that unusual constructions shed light on more general issues, and can illuminate what is required for a complete account of language.
\end{abstract}

Constructions - form and meaning pairings - have been the basis of major advances in the study of grammar since the days of Aristotle. Observations about specific linguistic constructions have shaped our understanding of both particular languages and the nature of language itself. But only recently has a new theoretical approach emerged that allows observations about constructions to be stated directly, providing long-standing traditions with a framework that allows both broad generalizations and more limited patterns to be analyzed and accounted for fully. This is in contrast to the mainstream 'generative' approach to language, which has held sway for the past several decades, beginning with Chomsky in 1957 [1].

Many linguists with varying backgrounds have recently converged on several key insights that have given rise to a new family of approaches, here referred to as 'constructionist' approaches [2-23]. Constructionist approaches share certain foundational ideas with the mainstream generative approach. Both approaches agree that it is essential to consider language as a cognitive (mental) system; both approaches acknowledge that there must be a way to combine structures to create novel utterances, and both approaches recognize that a non-trivial theory of language learning is needed.

In other ways, constructionist approaches contrast sharply with the mainstream generative approach. The latter has held that the nature of language can best be revealed by studying formal structures independently of their semantic or discourse functions. Ever increasing layers of abstractness have characterized the formal representations. Meaning is claimed to derive from the mental dictionary of words, with functional differences between formal patterns being largely ignored. Semiregular patterns and unusual patterns are viewed as 'peripheral,' with a narrow band of data seen as relevant to

Corresponding author: Adele E. Goldberg (agoldbrg@uiuc.edu). the 'core' of language. Mainstream generative theory argues further that the complexity of core language cannot be learned inductively by general cognitive mechanisms and therefore learners must be hard-wired with principles that are specific to language ('universal grammar').

\section{Tenets of constructionist approaches}

Each basic tenet outlined below is shared by most constructionist approaches. Each represents a major divergence from the mainstream generative approach and, in many ways, a return to a more traditional view of language.

Tenet 1. All levels of description are understood to involve pairings of form with semantic or discourse function, including morphemes or words, idioms, partially lexically filled and fully abstract phrasal patterns. (See Table 1)

Tenet 2. An emphasis is placed on subtle aspects of the way we conceive of events and states of affairs.

Tenet 3. A 'what you see is what you get' approach to syntactic form is adopted: no underlying levels of syntax or any phonologically empty elements are posited.

Tenet 4. Constructions are understood to be learned on the basis of the input and general cognitive mechanisms (they are constructed), and are expected to vary crosslinguistically.

Tenet 5. Cross-linguistic generalizations are explained by appeal to general cognitive constraints together with the functions of the constructions involved.

Tenet 6. Language-specific generalizations across constructions are captured via inheritance networks much like those that have long been posited to capture our non-linguistic knowledge.

Tenet 7. The totality of our knowledge of language is captured by a network of constructions: a 'construct-i-con.'

Each of these tenets is explained in a subsequent section below.

\section{Constructions: what they are}

Constructions are stored pairings of form and function, including morphemes, words, idioms, partially lexically filled and fully general linguistic patterns. Examples are given in Table 1.

Any linguistic pattern is recognized as a construction as long as some aspect of its form or function is not strictly predictable from its component parts or from other constructions recognized to exist. In addition, many 
Table 1. Examples of constructions, varying in size and complexity; form and function are specified if not readily transparent

\begin{tabular}{|c|c|c|}
\hline Construction & Form/Example & Function \\
\hline Morpheme & e.g. anti-, pre-, -ing & \\
\hline Word & e.g. Avocado, anaconda, and & \\
\hline Complex word & e.g. Daredevil, shoo-in & \\
\hline Idiom (filled) & e.g. Going great guns & \\
\hline Idiom (partially filled) & e.g. Jog $\langle$ someone's $\rangle$ memory & \\
\hline $\begin{array}{l}\text { Covariational-Conditional } \\
\text { construction [10] }\end{array}$ & $\begin{array}{l}\text { Form: The Xer the } \\
\text { Yer (e.g. The more you think about it, } \\
\text { the less you understand) }\end{array}$ & Meaning: linked independent and dependent variables \\
\hline $\begin{array}{l}\text { Ditransitive } \\
\quad \text { (double-object) } \\
\text { construction }\end{array}$ & $\begin{array}{l}\text { Form: Subj [V Obj1 } \\
\text { Obj2] (e.g. He gave her a Coke; He baked her a muffin) }\end{array}$ & Meaning: transfer (intended or actual) \\
\hline Passive & $\begin{array}{l}\text { Form: Subj aux VPpp }\left(\mathrm{PP}_{\text {by }}\right) \text { (e.g. The armadillo was hit } \\
\text { by a car) }\end{array}$ & $\begin{array}{l}\text { Discourse function: to make undergoer topical and/or } \\
\text { actor non-topical }\end{array}$ \\
\hline
\end{tabular}

constructionist approaches argue that patterns are stored even if they are fully predictable as long as they occur with sufficient frequency [24-29].

Unlike mainstream generative grammar, the constructionist framework emphasizes the semantics and distribution of particular words, grammatical morphemes, and cross-linguistically unusual phrasal patterns. The hypothesis behind this methodology is that an account of the rich semantic, pragmatic, and complex formal constraints on these patterns readily extends to more general, simple or regular patterns.

As an example of an unusual pattern, consider the Covariational Conditional construction in Table 1 (e.g. 'The more you think about it, the less you understand'). The construction is interpreted as involving an independent variable (identified by the first phrase) and a dependent variable (identified by the second phrase). The word the normally occurs at the beginning of a phrase headed by a noun. But in this construction it requires a comparative phrase. The two major phrases of the construction resist classification as either noun phrases or clauses. The requirement that two phrases of this type be juxtaposed without conjunction is another non-predictable aspect of the pattern. Because the pattern is not strictly predictable, a construction is posited that specifies the particular form and semantic function involved [10].

Other unusual constructions include those in Table 2. Although some of the patterns are primarily used colloquially, they are part of every native speaker's repertoire of English. (The stranded preposition construction is unusual not by virtue of its being prescriptively dispreferred, but in that it is found only in a few Germanic languages).

More common patterns such as passive, topicalization

Table 2. Productive or semi-productive constructions that are unusual across languages and must be learned on the basis of the input

\begin{tabular}{|lc|}
\hline time away construction & Twistin the night away [13] \\
What's X doing $\mathrm{Y}$ ? & What's that fly doing \\
& in my soup? [30] \\
Nominal Extraposition construction & It's amazing the difference! [31] \\
Mad Magazine construction & Him, a doctor?! [32] \\
Noun-Pronoun-Noun (N P N) & house by house; day \\
construction & after day [12] \\
Stranded preposition construction & Who did he give \\
& that to? \\
\hline
\end{tabular}

and relative clauses are understood to be learned pairings of form and (semantic or discourse) function - that is, they are also constructions. Each pairs certain formal properties with a certain communicative function.

Even basic sentence patterns of a language can be understood to involve constructions. That is, the main verb can be understood to combine with an argument-structure construction (e.g. transitive, intransitive, ditransitive constructions, etc.) [7]. The alternative is to assume that the form and general interpretation of basic sentence patterns are determined by semantic and/or syntactic information specified by the main verb. The sentence patterns given in (1) and (2) indeed appear to be determined by the specifications of give and put respectively:

(1) Chris gave Pat a ball.

(2) Pat put the ball on the table.

Give is a three-argument verb: an act of giving requires three characters: a giver (or agent), a recipient, and something given (or 'theme'). It is therefore expected to appear with three phrases corresponding to these three roles. In (1), for instances, Chris is agent, Pat is recipient, and a ball is theme. Put, another three-argument verb, requires an agent, a theme (object that undergoes the change of location) and a final location of the theme's motion. It appears with the corresponding three arguments in (2). However, whereas (1) and (2) represent perhaps the prototypical case, in general the interpretation and form of sentence patterns of a language are not reliably determined by independent specifications of the main verb. For example, it is implausible to claim that sneeze has a three-argument sense, and yet it can appear as such in (3). The patterns in (4)-(6) are likewise not naturally attributed to the main verbs:

(3) 'He sneezed his tooth right across town.' (Robert Munsch, Andrew's Loose Tooth)

(4) 'She smiled herself an upgrade.' (Douglas Adams, Hitchhiker's Guide to the Galaxy, Harmony Books)

(5) 'We laughed our conversation to an end.' (J. Hart. Sin Ivy Books, New York)

(6) 'They could easily co-pay a family to death.' (New York Times, 1/14/02)

Examples need not be particularly novel to make the point. Verbs typically appear with a wide array of 
complement configurations. Consider the verb slice and the various constructions in which it can appear (labeled in parentheses):

(7)

a. He sliced the bread. (transitive)

b. Pat sliced the carrots into the salad. (caused motion)

c. Pat sliced Chris a piece of pie. (ditransitive)

d. Emeril sliced and diced his way to stardom. (way construction)

e. Pat sliced the box open. (resultative)

In all of these expressions slice means to cut with a sharp instrument. It is the argument-structure constructions that provide the direct link between surface form and general aspects of the interpretation, such as something acting on something else (7a), something causing something else to move(7b), someone intending to cause someone to receive something (7c), someone moving somewhere(7d), someone causing something to change state $(7 \mathrm{e})[7,33]$.

Thus constructions can be seen to be essential to an effective account of both unusual or especially complex patterns, and of the basic, regular patterns of language.

\section{The functions of constructions}

Different surface forms are typically associated with slightly different semantic or discourse functions. Take for example, the 'ditransitive' construction, which involves the form, Subject-Verb-Object1-Object2, as in (1), (8b) and $(9 \mathrm{~b})$.

(8)

(9)

a. Liza bought a book for Zach.

b Liza bought Zach a book.

a. Liza sent a book to storage.

b. Liza sent Stan a book.

c. ??Liza sent storage a book.

The ditransitive form evokes the notion of transfer or 'giving'. This is in contrast to possible paraphrases. For example, whereas (8a) can be used to mean that Liza bought a book for a third party because Zach was too busy to buy it himself, (8b) can only mean that Liza intended to give Zach the book. Similarly whereas (9a) can be used to entail caused motion to a location (the book is caused to go to storage), the ditransitive pattern requires that the goal argument be an animate being, capable of receiving the transferred item (cf. 9b, 9c). As is clear from considering the paraphrases, the implication of transfer is not an independent fact about the words involved. Rather the implication of transfer comes from the ditransitive construction itself.

Other interpretations for the ditransitive can also be systematically related to the notion of transfer, in that they imply that the transfer will occur if certain satisfaction conditions evoked by the main verb occur (10a), that transfer will not occur (10b), or that the antonymic relation of giving occurs - that of taking away (10c). Even examples such as 'Cry me a river' can be related to the notion of giving via a metaphorical extension [7].
(10)

a. Liza guaranteed Zach a book. (If the guarantee is satisfied, Z. will receive a book)

b. Liza refused Zach a book. (Liza caused Zach not to receive a book)

c. Liza cost Zach his job. (Liza causes Zach to lose his job).

In addition to semantic generalizations there also exist generalizations about 'information structure' properties of the construction, or the way in which a speaker's assumptions about the hearer's state of knowledge and consciousness at the time of speaking is reflected in surface form. In particular, there is a statistically reliable tendency for the recipient argument to have already been mentioned in the discourse (often encoded by a pronoun) as compared with prepositional paraphrases $[9,34,35]$. Facts about the use of entire constructions, including register (e.g. formal or informal), dialect variation and so on, are stated as part of the construction as well. Because they specify a surface form and a corresponding function, constructionist approaches provide a direct way of accounting for these facts.

\section{The form of constructions}

To capture differences in meaning or discourse properties between surface forms, constructionist theories do not derive one construction from another, as is commonly done in mainstream generative theory. An actual expression or 'construct' typically involves the combination of at least half a dozen different constructions. For example, the construct in Fig. 1a involves the list of constructions given in Fig. 1b.

Note that 'surface form' need not specify a particular word order, nor even particular grammatical categories, although there are constructions that do specify these features. For example, the ditransitive construction (in Fig. 1 and discussed in the previous section) is characterized in terms of a set of argument types. The overt order of arguments in the ditransitive construction in Fig. 1 is determined by a combination of a Verb-Phrase (VP) construction with the Question construction, the latter allowing the 'theme' argument (represented by What) to appear in the sentence-initial position.

Constructions can be combined freely to form actual expressions as long as they are not in conflict. For example, the specification of the ditransitive construction that

(a) [ What did Liza buy the child? ]

(b) 1. Liza, buy, the, child, what, did constructions (i.e. words)

2. Ditransitive construction

3. Question construction

4. Subject-Auxiliary inversion construction

5. VP construction

6. NP construction

$\overline{\text { TRENDS in Cognitive Sciences }}$

Fig. 1. (a) An expression, or 'construct', that is a combination of the constructions shown in (b), color-coded to the appropriate parts of the expression (VP, VerbPhrase; NP, Noun-Phrase). See text for discussion. 
requires an animate recipient argument conflicts with the meaning of storage in $(9 \mathrm{c})$ resulting in unacceptability. The observation that language has an infinitely creative potential [1,36] is accounted for, then, by the free combination of constructions.

\section{Learning constructions}

The fourth tenet states that constructions are understood to be learned on the basis of positive input and to vary across languages. This idea highlights a major difference between most constructional approaches and most mainstream generative approaches, as the latter have argued that learners must be hard-wired with principles specific to a language faculty, that is, to possess a 'universal grammar' ([37]; see also [21]).

Crucially, all linguists recognize that a wide range of semi-idiosyncratic constructions exist in every language, constructions that cannot be accounted for by general, universal or innate principles or constraints (see examples in Table 2). Mainstream generative theory has taken the position that these constructions exist only on the 'periphery' of language, and that therefore they need not be the focus of linguistic or learning theorists [37]. Constructionist approaches, on the other hand, have zeroed in on these constructions, arguing that whatever means we use to learn these patterns can easily be extended to account for so-called 'core' phenomena. In fact, by definition, the core phenomena are more regular, and also tend to occur more frequently within a given language. Therefore if anything, they are likely to be easier to learn. Because every linguist would presumably agree that the 'peripheral', difficult cases must be learned inductively on the basis of the input, constructionist theories propose that there is no reason to assume that the more general, regular, frequent cases cannot possibly be learned in this way.

In fact, constructionist theories argue that language must be learnable from positive input together with fairly general cognitive abilities $[18,29,38]$, because the diversity and complexity witnessed does not yield to accounts that assume that cross-linguistic variation can be characterized in terms of a finite set of parameters [37]. Research in this area is quickly gaining momentum. Several constructionists have made good on the promise to explain how particular constructions are learned [26,27]. It turns out that the input need not be nearly as impoverished as is sometimes assumed [39]; analogical processes can be seen to be viable once function as well as form is taken into account $[40,41]$; there is good reason to think that children's early grammar is quite conservative, with generalizations emerging only slowly [29,42,43]; and the ability to record transitional probabilities and statistical generalizations in the input has proven a powerful means by which to learn certain types of generalizations [44].

This approach takes a somewhat different view from mainstream generative theory of what is universal about language. Linguists talk of certain constructions as existing in many languages, for example, the passive construction, relative clause construction, question construction, and so forth. However, two constructions in different languages can be identified as instances of the same construction if and only if their form and function is identical once other constructions in the language that might differ are factored out. In fact, this rarely occurs except in cases of shared diachronic history or language contact $[20,45,46]$. What is truly remarkable is the degree to which human languages differ from one another, given that all languages need to express roughly the same types of messages. Constructionist approaches anticipate such fairly wide variability across languages $[47,48]$.

We can understand what is actually intended by references to the 'same' construction in unrelated languages as types of constructions. Two constructions might be, for example, of the passive type in that they share certain functional and formal characteristics even if they are not identical. That is, two constructions in different languages can be identified as instances of the same type of construction if and only if they serve a closely related function and form.

\section{Cross-linguistic generalizations}

A driving question behind much of linguistic research is what is the typology of possible constructions and what constrains it? Constructionist approaches often turn to grammar-external explanations such as universal functional pressures, iconic principles, and processing and learning constraints to explain such empirically observable cross-linguistic generalizations. For example, certain generalizations about how form and meaning tend to be linked across languages can be explained by appeal to iconic and analogical processes [6,35,49-51]. Constraints on long-distance dependency constructions (traditional 'island constraints') appear to yield to processing explanations that take into account the function of the constructions involved [19,52-54]. Processing accounts have also been suggested to account for certain alternative word-order options $[55,56]$.

Even among generative linguists there has been a trend towards the view that many constraints on language that have traditionally been seen as requiring recourse to innate stipulations specific to language can actually be explained by general cognitive mechanisms. For example, the fact that that all languages appear to have noun and verb (and, possibly, adjective) categories may be explained by the existence of corresponding basic semantic categories [57]. In a recent paper, Hauser, Chomsky and Fitch go so far as to suggest that the only language-specific innate ability that is absolutely required is recursion, and they raise the point that even that might turn out not to be specific to language [58] (see also Box 1. Questions for Future Research).

\section{Intra-language generalizations}

Inheritance hierarchies have long been found useful for representing all types of knowledge, for example, our knowledge of concepts. The construction-based framework captures linguistic generalizations within a particular language via the same type of inheritance hierarchies $[2,59,60]$. Broad generalizations are captured by constructions that are inherited by many other constructions; more limited patterns are captured by positing constructions at various midpoints of the hierarchical network. 


\section{Box 1. Questions for Future Research}

- Do there exist generalizations about form that do not have even an abstract, family-resemblance or radial category type generalization about function associated with them?

- Does learning one construction facilitate learning other related constructions?

- What is the relationship between type and token frequencies in acquisition?

- If principles that are specific to language are not hardwired into our brains, how exactly do we differ from other primates who do not develop human-like languages?

- How great a role do general processing principles play in determining possible languages?

Exceptional patterns are captured by low-level constructions. For example, the 'What's $X$ doing $Y$ ?' construction, which has a fixed form and connotes some sort of unexpectedness, captures a pattern in English grammar. It inherits properties from several other more general constructions, including the Left Isolation, the SubjectAuxiliary Inversion, the Subject-Predicate and the VerbPhrase constructions [30].

\section{Constructions all the way down}

What makes a theory that allows for constructions a 'construction-based' theory is Tenet 7: the idea that the network of constructions captures our knowledge of language in toto - in other words, it's constructions all the way down.

\section{Conclusion}

Constructionist theories set out to account for all of our knowledge of language as patterns of form and function. That is, the constructionist approach does not assume that language should be divided up into 'core' grammar and the to-be-ignored 'periphery.' In identifying constructions, an emphasis is placed on subtle aspects of construal and on surface form. Cross-linguistic generalizations are explained by appeal to general cognitive constraints together with the functions of the constructions involved. Language-specific generalizations across constructions are captured via inheritance networks. The inventory of constructions, which includes morphemes or words, idioms, partially lexically filled and fully abstract phrasal patterns, is understood to be learned on the basis of the input together with general cognitive mechanisms.

\section{Acknowledgements}

I am grateful to Ray Jackendoff, Fritz Newmeyer, Devin Casenhiser, Mike Tomasello, Ali Yazdani and the anonymous referees for advice on an earlier draft. I am sure I will regret any I failed to heed.

\section{References}

1 Chomsky, N. (1957) Syntactic Structures, Mouton

2 Lakoff, G. (1987) Women, Fire and Dangerous Things: What Categories Reveal About the Mind, University of Chicago Press

3 Langacker, R.W. (1987/1991) Foundations of Cognitive Grammar (Vols I \& II), Stanford University Press

4 Fillmore, C.J.et al. (1988) Regularity and idiomaticity in grammatical constructions: the case of let alone. Language 64, 501-538
5 Wierzbicka, A. (1988) The Semantics of Grammar, John Benjamins Publishing

6 Lambrecht, K. (1994) Information Structure and Sentence Form, Cambridge University Press

7 Goldberg, A.E. (1995) Constructions: A Construction Grammar Approach to Argument Structure, Chicago University Press

8 Gleitman, L. et al. (1996) 'Similar' and similar concepts. Cognition 58, $321-376$

9 Thompson, S.A. (1990) Information flow and dative shift in english discourse. In Development and Diversity: Linguistic Variation Across Time and Space (Edmondson, J., ed.), pp. 239-253, Summer Institute of Linguistics, Dallas

10 Culicover, P.W. and Jackendoff, R. (1999) The view from the periphery: the English comparative correlative. Linguist. Inq. 30, 543-571

11 Zwicky, A. (1994) Dealing out meaning: fundamentals of syntactic constructions. Berkeley Linguist. Soc. 20, 611-625

12 Williams, E. (1994) Remarks on lexical knowledge. Lingua 92, 7-34

13 Jackendoff, R. (1997) Twistin' the night away. Language 73, 534-559

14 Sag, I.A. (1997) English relative clause constructions. J. Linguist. 33, 431-484

15 Webelhuth, G. and Ackerman, F. (1998) A Theory of Predicates, CSLI Publications/Cambridge University Press

16 Iwata, S. (1998) A Lexical Network Approach to Verbal Semantics, Kaitakusha, Tokyo

17 Shibatani, M. (1999) Dative subject constructions 22 years later. Stud. Linguist. Sci. 29, 45-76

18 Culicover, P.W. (1999) Syntactic Nuts: Hard Cases in Syntax, Oxford University Press

19 van Valin, R. Jr (1998) The acquisition of WH-questions and the mechanisms of language acquisition. In The New Psychology of Language: Cognitive and Functional Approaches to Language Structure (Tomasello, M., ed.), pp. 221-249, Erlbaum

20 Croft, W. (2001) Radical Construction Grammar, Oxford University Press

21 Jackendoff, R. (2002) Foundations of Language, Oxford University Press

22 Bybee, J. (2001) Main clauses are innovative, subordinate clauses are conservative: consequences for the nature of constructions. In Complex Sentences in Grammar and Discourse: Essays in Honor of Sandra A. Thompson (Bybee, J. and Noonan, M., eds) pp. 1-17, John Benjamins

23 Booij, G. (2002) Constructional idioms, morphology, and the dutch lexicon. J. Germanic Linguist. 144, 301-329

24 Langacker, R.W. (1988) A usage-based model. In Topics in Cognitive Linguistics (Rudzka-Ostyn, B., ed.), pp. 127-161, John Benjamins

25 Barlow, M. and Kemmer, S. (2000) Usage Based Models of Grammar, CSLI Publications/Cambridge University Press

26 Israel, M. et al. (2000) From states to events: the acquisition of english passive participles. Cogn. Linguist. 11, 1-27

27 Diessel, H. and Tomasello, M. (2001) The acquisition of finite complement clauses in English: a usage based approach to the development of grammatical constructions. Cogn. Linguist. 12, 97-141

28 Verhagen, A. (2002) From parts to wholes and back again. Cogn. Linguist. 1, 13-14

29 Tomasello, M. Constructing a Language: A Usage-Based Theory of Language Acquisition. Harvard University Press (in press)

30 Kay, P. and Fillmore, C.J. (1999) Grammatical constructions and linguistic generalizations: the What's $\mathrm{X}$ doing $\mathrm{Y}$ ? construction. Language 75, 1-34

31 Michaelis, L.A. and Lambrecht, K. (1996) Toward a construction-based model of language function: the case of nominal extraposition. Language 72, 215-247

32 Lambrecht, K. (1990) 'What, me worry?' Mad Magazine sentences revisited. Proc. 16th Annu. Meet. Berkeley Linguist. Soc., pp. 215-228, University of California

33 Goldberg, A.E. Argument realization: the role of constructions, lexical semantics and discourse factors. In Construction Grammar(s): Cognitive and Cross-Language Dimensions (Fried, M. and Östman, J.O., eds.), John Benjamins (in press)

34 Erteschik-Shir, N. (1979) Discourse constraints on dative movement. In Syntax and Semantics (Laberge, S. and Sankoff, G., eds) pp. 441-467, Academic Press 
35 Wasow, T. (2002) Postverbal Behavior, CSLI Publications

36 Chomsky, N. (1965) Aspects of the Theory of Syntax, MIT Press

37 Chomsky, N. (1981) Lectures on Government and Binding, Foris, Dordrecht

38 Elman, J. et al. (1996) Rethinking Innateness: A Connectionist Perspective on Development, MIT Press

39 Pullum, G.K. and Scholz, B.C. (2002) Empirical assessment of stimulus poverty arguments. Linguist. Rev. 19, 9-50

40 Goldberg, A.E. (1999) The Emergence of argument structure semantics. In The Emergence of Language (MacWhinney, B., ed.), pp. 197-212, Erlbaum

41 Israel, M. (2002) Consistency and creativity in first language acquisition. Proc. Berkeley Linguist. Soc., p. 29

42 Lieven, E.V.M. et al. (1997) Lexically-based learning and early grammatical development. J. Child Lang. 24, 187-219

43 Tomasello, M. (2000) Do young children have adult syntactic competence? Cognition 74, 209-253

44 Saffran, J.R. (2001) The use of predictive dependencies in language learning. J. Mem. Lang. 44, 493-515

45 Birner, B. and Ward, G. (1998) Information Status and Noncanonical Word Order in English, John Benjamins

46 Zhang, N. (1998) The interactions between construction meaning and lexical meaning. Linguistics 36, 957-980

47 Foley, W.A. and van Valin, R. Jr (1984) Functional Syntax and Universal Grammar, Cambridge University Press

48 Garry, J. and Rubino, C., eds. (2001) Facts about the World's Languages: An Encyclopedia of the World's Major Languages Past and Present. H.W. Wilson
49 Haiman, J. (1985) Iconicity in Syntax, Cambridge University Press

50 Givón, T. (1991) Isomorphism in the grammatical code: cognitive and biological considerations. Studies Lang. 1, 85-114

51 Kemmer, S. and Verhagen, A. (2002) The grammar of causatives and the conceptual structure of events. Mouton Classics: From Syntax to Cognition, From Phonology to Text, pp. 451-491, Mouton de Gruyter

52 Kluender, R. (1998) On the distinction between strong and weak islands: a processing perspective. Syntax Semantics 29, 241-279

53 Kluender, R. and Kutas, M. (1993) Subjacency as a processing phenomenon. Lang. Cogn. Process. 8, 573-633

54 Erteschik-Shir, N. (1998) The syntax-focus structure interface. In Syntax and Semantics Vol. 29: The Limits of Syntax (Culicover, P. and McNally, L., eds.), pp. 211-240, Academic Press

55 Hawkins, J. (1994) A Performance Theory of Order and Constituency, Cambridge University Press

56 Yamashita, H. and Chang, F. (2001) 'Long before short' preference in the production of a head-final language. Cognition 81, B45-B55

57 Baker, M. (2003) Verbs, Nouns, and Adjectives: Their Universal Grammar. Cambridge University Press (in press)

58 Hauser, M.D. et al. (2002) The faculty of language: what is it, who has it, and how did it evolve? Science 298, 1569-1579

59 Pollard, C.J. and Sag, I. (1994) Head-Driven Phrase Structure Grammar, CSLI Publications/Cambridge University Press

60 Goldberg, A.E. Words by default: inheritance and the Persian Complex Predicate Construction. In Mismatch: Form-Function Incongruity and the Architecture of Grammar (Francis, E. and Michaelis, L., eds.), CSLI Publications (in press)

\section{News \& Features on BioMedNet}

Start your day with BioMedNet's own daily science news, features, Research Update articles and special reports. Every two weeks, enjoy BioMedNet Magazine, which contains free articles from Trends, Current Opinion, Cell and Current Biology. Plus, subscribe to Conference Reporter to get daily reports direct from major life science meetings.

\section{http://news.bmn.com}

Here is what you will find in News \& Features:

\section{Today's News}

Daily news and features for life scientists.

Sign up to receive weekly email alerts at http://news.bmn.com/alerts

\section{Special Report}

Special in-depth report on events of current importance in the world of the life sciences.

\section{Research Update}

Brief commentary on the latest hot papers from across the life sciences, written by laboratory researchers chosen by the editors of the Trends and Current Opinions journals, and a panel of key experts in their fields.

Sign up to receive Research Update email alerts on your chosen subject at http://update.bmn.com/alerts

\section{BioMedNet Magazine}

BioMedNet Magazine offers free articles from Trends, Current Opinion, Cell and BioMedNet News, with a focus on issues of general scientific interest. From the latest book reviews to the most current Special Report, BioMedNet Magazine features Opinions, Forum pieces, Conference Reporter, Historical Perspectives, Science and Society pieces and much more in an easily accessible format. It also provides exciting reviews, news and features, and primary research. BioMedNet Magazine is published every 2 weeks. Sign up to receive weekly email alerts at http://news.bmn.com/alerts

\section{Conference Reporter}

BioMedNet's expert science journalists cover dozens of sessions at major conferences, providing a quick but comprehensive report of what you might have missed. Far more informative than an ordinary conference overview, Conference Reporter's easy-to-read summaries are updated daily throughout the meeting.

Sign up to receive email alerts at http://news.bmn.com/alerts 